Iranian Journal of Pathology | ISSN: 2345-3656

\title{
Molecular Genotyping of Acinetobacter baumannii Species Isolated from Patients in Tehran, Iran, by Repetitive Element PCR Fingerprinting
}

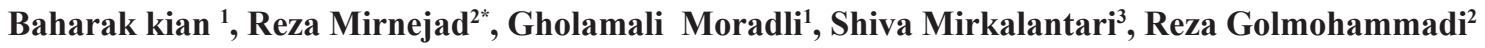 \\ 1. Dept. of Microbiology, Islamic Azad University of Saveh Branch, Tehran, Iran \\ 2. Molecular Biology Research Center, Systems Biology and Poisonings Institute, Baqiyatallah \\ University of Medical Sciences, Tehran, Iran. \\ 3. Dept. Microbiology, School of Medicine, Iran University of Medical Sciences, Tehran, Iran
}

\begin{tabular}{c} 
KEYWORDS \\
\hline Acinetobacter; \\
Antibacterial Resistance; \\
REP-PCR \\
\\
\hline
\end{tabular}

Article Info

Received 18 Jul 2016;

Accepted 13 Feb 2017;

Published Online 17 July 2018;

\section{ABSTRACT}

Background \& objective: Acinetobacter baumannii is an opportunistic pathogen with high pathogenic and antibiotic-resistance potential and is also considered as one of the main nosocomial agents, specifically in the intensive care units (ICUs). It is highly important to use molecular biology methods in the epidemiological studies, determine the source of infection, and understand the relationships and distributional patterns of pathogens. Therefore, the current study aimed to determining the similar molecular types in the A. baumannii species isolated from patients in Tehran, Iran, by the repetitive element PCR fingerprinting (REP-PCR) method.

Methods: A total of 350 clinical samples were collected from patients admitted to different hospital in Tehran, assessed to identify Acinetobacter spp., based on the special culture media and biochemical test results. The resistance of isolates was evaluated against 11 different antibiotics. The cefepime and ceftazidime were assessed by the minimum inhibitory concentration (MIC) method, based on serial dilutions. The genome of isolated strains was extracted using the modified boiling method and amplified in REP-PCR technique using specific primers.

Results: In the current study, out of 120 isolates of Acinetobacter spp., 100 (76.9\%) were identified as $A$. baumannii, mostly from ICUs and infectious diseases wards. The isolates of $A$. baumannii in the current study mostly showed antimicrobial resistance against cefepime and ceftazidime, and had the highest sensitivity to polymyxin $\mathrm{B}$. About $70 \%$ of $A$. baumannii isolates in the current study were resistant to 3 or more antibiotics. According to dendrogram analyses, the patterns were classified to A- I with the maximum population (36\%) of group A. All genotypes of Acinetobacter spp. in the current study showed resistance against carbapenems and aminoglycosides.

Conclusion: High similarities between the isolates in the current study indicated the high distribution of $A$. baumannii species in the hospitals of Tehran.

Reza Mirnejad, Molecular Biology Research Center, Systems Biology and Poisonings Institute, Baqiyatallah University of Medical Sciences, Tehran, Iran. E-mail: rmirnejad@bmsu.ac.ir

Copyright (C) 2018, IRANIAN JOURNAL OF PATHOLOGY. This is an open-access article distributed under the terms of the Creative Commons Attribution-noncommercial 4.0 International License which permits copy and redistribute the material just in noncommercial usages, provided the original work is properly cited.

\section{Introduction}

In recent years, due to prolonged hospitalization and also increasing daily use of invasive methods such as cardiovascular catheters and ventilators in the diagnostic procedures and treatment of patients, risk of nosocomial infections increased (1-4). Nosocomial infections increase the costs, duration of hospitalization, transmission of infections to other patients, and mortality. Different microorganisms such as Pseudomonas aeruginosa, Staphylococcus aureus, Esch- erichia coli, Enterococcus spp., and Acinetobacter baumannii, cause nosocomial infections with different dissemination patterns in the countries $(2,4)$. Acinetobacter baumannii is an opportunistic pathogen with high pathogenicity and antibacterial resistance, which was one of the main causes of nosocomial infections, especially in the intensive care units (ICUs), within the last 3 years (5-7). Recently, there is dramatic increase in the use of different molecular methods such as pulsed-field gel electrophoresis (PFGE), 
enzymatic cuts techniques, analysis of plasmids, and typing based on PCR in the epidemiological evaluations, finding the source of infection, and understanding the relationships and dissemination patterns of the pathogens $(8,9)$.

Molecular methods based on PCR, used for typing purposes are more stable and less dependent on growth factors. Such methods are time-effective and are used in finding the relationships between the microbial isolates and putting strains in specific groups. There are different bacterial typing PCR-based methods such as random amplification of polymorphic DNA (RAPD)PCR, arbitrarily primed (AP)-PCR, PCR-restriction fragment length polymorphism (RFLP), and repetitive element PCR fingerprinting (REP-PCR); each one includes advantages and disadvantages. Among the mentioned methods, the ones evaluating the repetitive elements in bacterial genome are widely used, due to the stability of such elements during evolution. One of the methods used for the sequencing purposes is REP-PCR. Methods such as enterobacterial repetitive intergenic consensus (ERIC)-PCR, 23SARDRA, 16SARDRA and etc. have more differentiating abilities and are also time-effective, compared to PCRRFLP and PFGE methods (10-12). Therefore, in the current study the REP-PCR technique was used for the molecular typing purposes in A. baumannii species isolated in Tehran, Iran.

\section{Materials and Methods}

\section{Samples and species}

In the current study, a total of 350 clinical samples of blood, urine, wound, trachea, etc., were collected from patients admitted to different hospitals in Tehran (Imam Khomeini, Baqiyatallah, Milad, etc.) from 2014 to 2015. The collected samples were transferred to the laboratory in brain-heart infusion (BHI) broth( Merck company, USA) .

\section{Isolation of Acinetobacter baumannii}

The clinical samples were cultured on blood agar and MacConkey agar ( Merck company, USA) and incubated for 24 hours at $37^{\circ} \mathrm{C}$. Then, the cultures were evaluated using specific media and biochemi- cal tests such as urease, OF (oxidation-fermentation), SIM (sulfide, iron, motility), MR/VP (methyl red and Voges-Proskauer), in addition to catalase, oxidase, and Simmons citrate tests as well as growth at $37^{\circ} \mathrm{C}$ and $42^{\circ} \mathrm{C}$ to identify different species of Acinetobacter.

\section{Susceptibility testing based on the disc diffu- sion method}

To determine the antimicrobial-resistant phenotypes, the disc diffusion method was used according to the guidelines of the Clinical and Laboratory Standards Institute (CLSI) (13). In the current study, 11 different antibiotic disks, purchased from MAST Company (Mast Diagnostics, Mast group Ltd., Merseyside, UK), and were used as follows:

cefepime $(30 \mu \mathrm{g})$, ceftriaxone $(30 \mu \mathrm{g})$, amikacin $(30 \mu \mathrm{g})$, imipenem $(10 \mu \mathrm{g})$, piperacillin-tazobactam $(110 \mu \mathrm{g})$, meropenem $(10 \mu \mathrm{g})$, gentamicin $(12 \mu \mathrm{g})$, tobramycin $(10 \mu \mathrm{g})$, tetracycline $(30 \mu \mathrm{g})$, ampicillin-sulbactam $(20 \mu \mathrm{g})$, and polymyxin B (300 $\mu \mathrm{g})$.

To assess the quality of test, E. coli ATCC 25922 and A. baumannii ATCC 19606 were used as negative and positive controls respectively (13).

\section{Minimum inhibitory concentration testing}

According to CLSI (2014) guidelines, a minimum concentration of an antibiotic, which inhibits bacterial growth, is referred to MIC. In the current study, MIC was assessed for Cefepime and Ceftazidime, based on the macro dilution method (13).

\section{DNA extraction and PCR amplification}

Genomic content of all A. baumannii isolates were extracted by the modified boiling method. For this purpose, a loopful of pure culture was dissolved in $100 \mu \mathrm{L}$ of saline solution and, then placed in a boiling water bath at $100^{\circ} \mathrm{C}$ for 20 minutes and immediately centrifuged in microtubes at $12000 \mathrm{~g}$ for 15 minutes. The supernatant contained bacterial DNA, which its purity was assessed on $0.8 \%$ agarose gel and the spectrophotometric method (14). The PCR reaction was performed in a total volume of $25 \mu \mathrm{L}$ including $12 \mu \mathrm{L}$ of $2 \mathrm{X}$ Master Mix (Ampliqon III 
Ltd., Denmark, containing $20 \mathrm{mM}$ dNTP, $1.5 \mathrm{mM}$ $\mathrm{MgCl} 2), 2 \mu \mathrm{L}(10 \mathrm{ngr} / \mu \mathrm{L})$ of DNA pattern, $1 \mu \mathrm{L}$ of primer containing $10 \mathrm{pmol}$ of each primer (reverse: 5 '-IIIGCGCCGICATCAGGC-3'; forward: 5'-ACGTCTTATCAGGCCTAC-3') and double distilled water to reach a total volume of $25 \mu \mathrm{L}$. PCR product was electrophoresed on 1\% agarose gel and, then, using GelClust software, DNA segments were analyzed based on Dice algorithm (distance matrix analysis), and the clones clustering was conducted by UPGMA

\section{Results}

In the current study, out of 120 species of Acinetobacter isolated from 350 hospitalized patients, 100 (76.9\%) isolates were identified as A. baumannii, 13 (11\%) as A. lwoffi, and $7(6 \%)$ as other species of Acinetobacter. Out of 100 isolated species, 40 were obtained from ICUs, 30 from infectious diseases wards, 20 from emergency rooms, and 10 from other wards. Among all A. baumannii species isolated in the current study, 40 (40\%) were obtained from blood samples, 27 (27\%) from tracheas, 12 (12\%) from wounds, $8(8 \%)$ from urine samples, and $13(13 \%)$ from unknown sources.

The highest antibiotic resistance in A. baumannii isolates was observed against cefepime, ceftriaxone, and amikacin, respectively; the lowest resistance was also reported against polymyxin B (Table 1). About $70 \%$ of A. baumannii isolates showed resistance against 3 or more antibiotics. Also, results of the current study indicated that none of the isolates was resistant against all antibiotics and all of them showed susceptibility at least to 1 antibiotic.

Among the isolated species in the current study, MIC for ceftazidime and cefepime were $\geq 128 \mu \mathrm{g} / \mathrm{mL}$ in $84 \%$ and $91 \%$ of the isolates, respectively.

Using REP1 and REP2 primer pairs, the presence of palindromic repeat sequences was assessed by REPPCR method. All 100 isolates of A. baumannii were assessed by this method and accordingly, 9 to 15 PCR amplifications were illustrated. According to dendrogram analysis and evaluation of segments obtained from the electrophoresis of REP-PCR products on 1\% gel agarose, 9 different patterns were obtained, which were categorized from A to I (chart 1). Evaluation of PCR patterns indicated that $36 \%$ of the isolates were belonging to group $\mathrm{A}, 4 \%$ to group $\mathrm{B}, 8 \%$ to group $\mathrm{C}$, $2 \%$ to group $\mathrm{D}, 10 \%$ to group $\mathrm{E}, 2 \%$ to group $\mathrm{F}, 8 \%$ to group G, $20 \%$ to group $\mathrm{H}$, and $10 \%$ to group I. Size of the segments ranged from -4 to $0.2 \mathrm{~kb}$.

To determine the patterns, only the bands $<3 \mathrm{~kb}$ or more $>0.2 \mathrm{~kb}$ were used. After the analysis of patterns by the visual method using GelClust software, dendrogram was constructed and accordingly, 9 genotypes were obtained. All genotypes of Acinetobacter spp. showed resistance against carbapenems and aminoglycosides in the current study.

Results of the current study showed that A. baumannii species isolated from patients admitted to Imam Khomeini, Milad, and Rasoul Akram hospitals had the same genotype and the species isolated from Baqiyatallah hospital had a different genotype, compared to other ones.

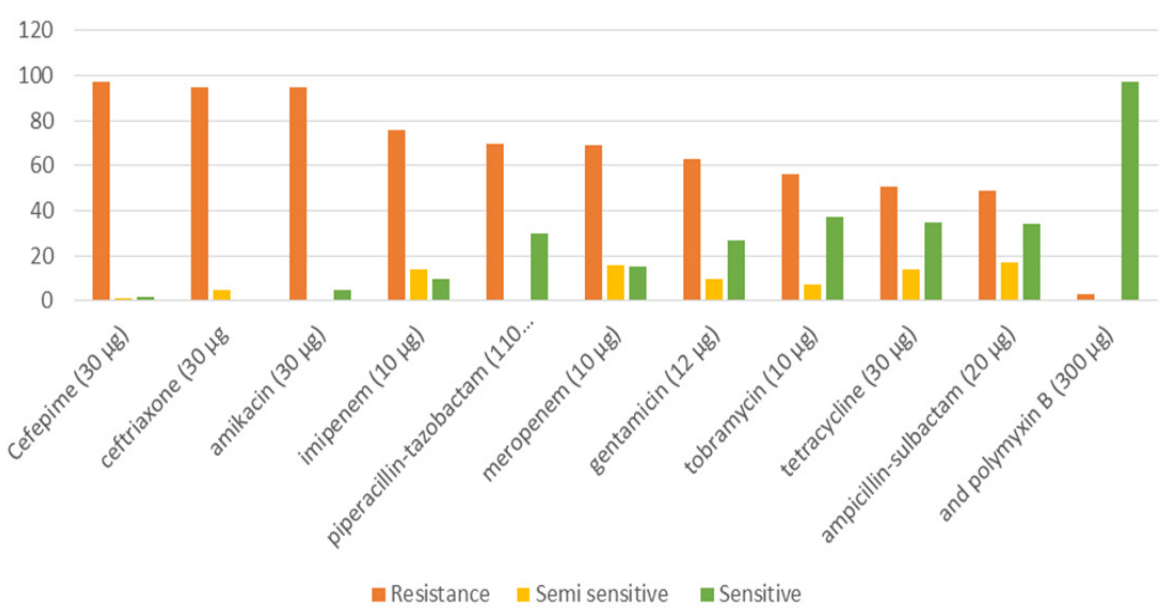

Figure 1. The frequency of antibiotic resistance among the A.baumannii isolates 


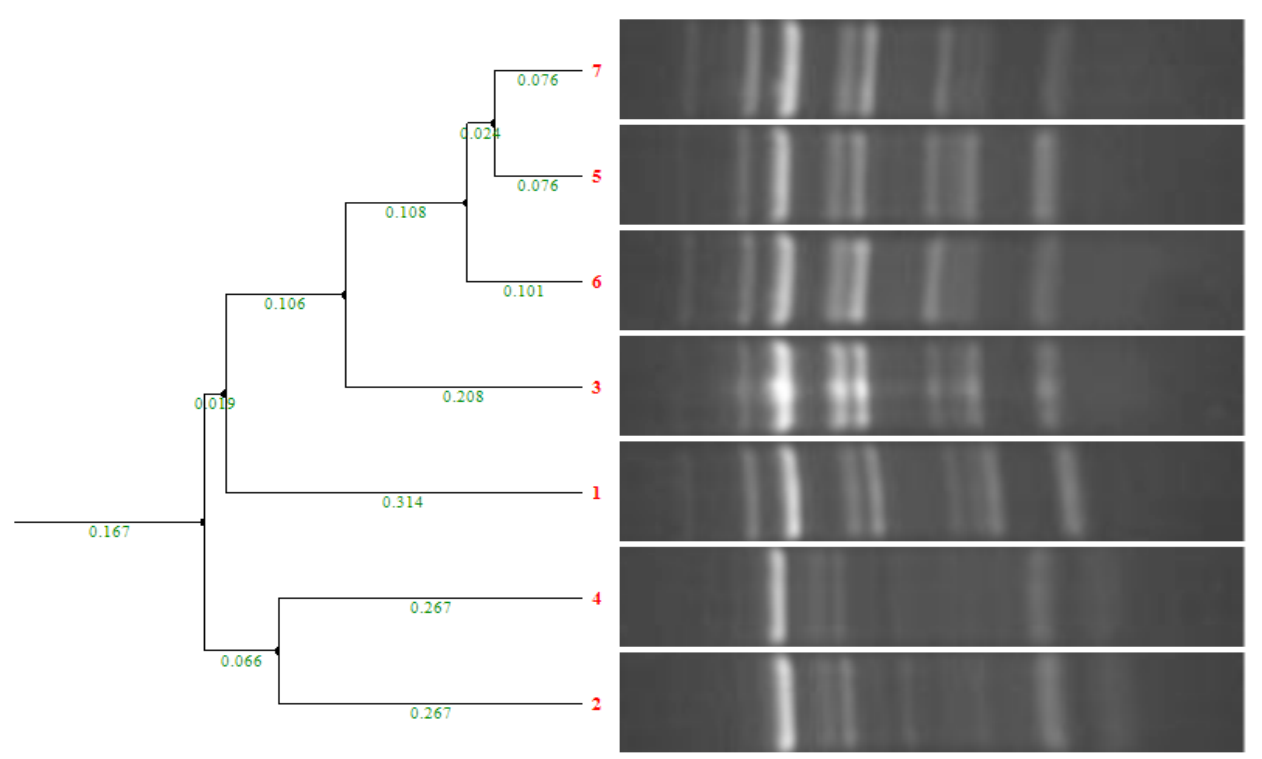

Chart 1. Dendrogram constructed based on REP-PCR amplifications of A. baumannii isolates based on their similarity coefficient (Dice coefficient).

\section{Discussion}

Acinetobacter baumannii is one of the pathogens involved in nosocomial infections, which its cases increase annually $(5,6)$. Similar to the results of the studies by Constantiniu et al. and Khalatabadi et al., which reported the frequency of $A$. baumannii $75 \%$ and $80 \%$, respectively $(15,16)$; the frequency of $A$. baumannii isolates was shown $83 \%$ in the current study, which was higher than those of other species of Acinetobacter. Resistance of $A$. baumannii against most of the routine antibiotics caused severe problems in controlling these bacteria. The current study was designed as A. baumannii is one of the main causes of recent nosocomial infections, especially in ICUs, its number is increasing, and it shows resistance to different antibiotics in different hospitals. Today, dissemination of resistance genes through plasmid transmission among bacteria is a severe problem in successful treatment of infections (17-21). According to the results of the current study, A. baumannii was mostly isolated from ICUs in the studied hospitals by $76 \%$. It was also indicated that the antibiotic resistance was high among the A. baumannii species isolated from hospitals; even about $70 \%$ of A. baumannii isolates were the multiresistant strains $(19,20)$. The isolated species of $A$. baumannii mostly showed resistance to cefepime, ceftriaxone, and amikacin. Results of the study by Kartbika and Rahar on the resistance pat- tern of these bacteria were consistent with those of the current study $(21,22)$, but in contradiction with the results of Ayan et al., which can be due to the different study design and time (23). According to the results of antibiogram in the current study, polymyxin B was the only antibiotic that was most effective against all A. baumannii isolates. Similarly, Mak et al., also reported polymyxin $\mathrm{B}$ as an effective antibiotic on $A$. baumannii (24).

Recently, using of different molecular methods is of great importance in the epidemiological evaluations, determining the source of infection, and understanding the dissemination pattern and associations of bacteria. The molecular methods are usually performed based on REP-PCR, which are less dependent on the bacterial growth variables and are more sustainable. Such methods are time-effective and are used in finding the relationships between the microbial isolates and putting strains in specific groups. Families of repeated sequences are available in the genomic content of different groups of bacteria, which are useful in genotyping purposes $(25,26)$. Repetitive element sequence based -PCR is one of the most useful methods in the sequencing of such segments. This method benefits from higher differentiating ability, compared with PCR-ERIC, ARDRA16S, and 23SARDRA, and is also time-effective compared with RFLP-PCR and PFGE methods (27). Evaluation of 120 genomic con- 
tents of A. baumannii by REP-PCR showed 9 clones among the species isolated from different hospitals in Tehran. Most of the A. baumannii isolates (36\%) were attributed to genotype A. In the study by Misbah et al., in Malaysia, 109 isolates of A. baumannii were categorized in 9 genotypes using REP-PCR method and most of the isolates attributed to 2 genotypes, which was almost consistent with the results of the current study (27). Most of the A. baumannii species in genotype A isolated from trachea and blood samples, which indicated that application of invasive instruments such as trachea and cardiovascular catheters during the therapeutic procedures may play a role in the dissemination of $A$. baumannii clones. In a study in China in 2009 on 49 isolates of A. baumannii using REP-PCR method, the isolates were categorized in 9 genotypes, out of which 2 genotypes were identified in 3 hospitals, 2 other genotypes in 1 hospital, and another genotype in 2 hospitals (28). Results of the study indicate a cross of $A$. baumannii in different hospitals, which was consistent with those of the current study, based on the dendrogram analysis on the same genotype among 3 hospitals in Tehran. Genotyping assessments indicated significant similarities among A. baumannii isolates in the current study. Bacterial species isolated from Baqiyatallah hospital in Tehran had various genotypes, different from the genotypes identified in other studies, which could be due to particular patients.

\section{Conclusion}

High similarities among the studied species indicated the dissemination of $A$. baumannii species isolated from different hospitals in Tehran. Dissemination of the bacteria can be done by physicians, personnel of the hospital, and medical equipment. Increase in the antibacterial resistance of $A$. baumannii, in addition to the obtained fingerprinting pattern, emphasized the need to design programs to apply more control and supervision over the hygiene standards in the hospitals.

\section{Acknowledgments}

This study was conducted in Molecular Biology
Research Center, Baqiyatallah University of Medical Sciences, thanks to the cooperation authors and the staff of the center.

\section{Conflicts of interest}

The authors declared no conflict of interest.

\section{References}

1. Boev C, Kiss E. Hospital-Acquired Infections: Current Trends and Prevention. Crit Care Nurs Clin North Am. 2017;29(1):51-65. https://doi. org/10.1016/j.cnc.2016.09.012 PMID:28160957

2. Lobdell KW, Stamou S, Sanchez JA. Hospital-acquired infections. Surg Clin North Am. 2012;92(1):65-77. $\quad$ https://doi.org/10.1016/j. suc.2011.11.003 PMID:22269261

3. Weisenberg S, Schuetz A, Alexander E, Eiss B, Behta M, Saiman L, Larone D, Jenkins S, Rhee K. Endemic Acinetobacter baumannii in New York hospital . PloS one. 2011;6(12):e28566. https://doi.org/10.1371/journal.pone.0028566 PMID:22180786 PMCID:PMC3236744

4. Weinstein R, Gaynes R, Edwards J. Overview of nosocomial infections caused by gram-negative bacilli. Clin Infect Dis. 2005;41(6):848-54. https://doi.org/10.1086/432803 PMID:16107985

5. Doughari HJ, Ndakidemi PA, Human IS, Benade S. The ecology, biology and pathogenesis of Acinetobacter spp. Microbes Environ. 2011;26(2):101-12. https://doi.org/10.1264/jsme2. $\underline{\text { ME10179 }}$ PMID: 21502736

6. Lee CR, Lee JH, Park M, Park KS, Bae IK, Kim YB,et al. Biology of Acinetobacter baumannii: Pathogenesis, Antibiotic Resistance Mechanisms, and Prospective Treatment Options. Front Cell Infect Microbiol. 2017;7:55. https://doi. org/10.3389/fcimb.2017.00055 PMID:28348979 PMCID:PMC5346588

7. Mirnejad R, Mostofi S, Masjedian F. Antibiotic resistance and carriage class 1 and 2 integrons in clinical isolates of Acinetobacter baumannii from Tehran, Iran. Asian Pac J Trop Biomed. 2013;3(2):140-5. https://doi.org/10.1016/ $\underline{\text { S2221-1691(13)60038-6 }} \quad$ PMID:23593593 PMCID:PMC3627174

8. Rafei R, Kempf M, Eveillard M, Dabboussi 
F, Hamze M, Joly-Guillou ML. Current molecular methods in epidemiological typing of Acinetobacter baumannii. Future Microbiol. 2014;9(10):1179-94. https://doi.org/10.2217/ fmb.14.63 PMID:25405887

9. Sabat AJ, Budimir A, Nashev D, Sá-Leão R, van Dijl Jm, Laurent F, et al. Overview of molecular typing methods for outbreak detection and epidemiological surveillance. Euro Surveill. 2013;18(4):20380. https://doi.org/10.2807/ $\underline{\text { ese.18.04.20380-en } \quad P M I D: \underline{23369389}}$

10. Singh A, Goering RV, Simjee S, Foley SL, Zervos MJ. Application of molecular techniques to the study of hospital infection. Clin Microbiol Rev. 2006;19(3):512-30. https://doi. org/10.1128/CMR.00025-05 PMID: 16847083 PMCID:PMC1539107

11. Hiett KL, Seal BS. Use of repetitive element palindromic PCR (rep-PCR) for the epidemiologic discrimination of foodborne pathogens. Methods Mol Biol. 2009;551:49-

58. https://doi.org/10.1007/978-1-60327-999-4_5 PMID: 19521866

12. Czaban SL, Sacha P, Wieczorek P, Kłosowska W, Krawczyk M, Ojdana D, Poniatowski B, Tryniszewska E. Rep-PCR genotyping of infectious Acinetobacter spp. strains from patients treated in Intensive Care Unit of Emergency Department (ICU of ED) - preliminary report. Adv Med Sci. 2013;58(1):164-71. https://doi. org/10.2478/v10039-012-0064-0 PMID:23612701

13. CLSI. Performance Standards for Antimicrobia Susceptibility Testing; Twenty-Fifth Informational Supplement; 2015. http://www.facm.ucl. ac.be/intranet/CLSI/CLSI-2015-M100-S25original.pdf

14. Mirnejad R, Babavalian $\mathrm{H}$, Moghaddam MM, Khodi S, Shakeri F. Rapid DNA extraction of bacterial genome using laundry detergents and assessment of the efficiency of DNA in downstream process using polymerase chain reaction. African Journal of Biotechnology. 2012;11(1):173-8. http://www. academicjournals.org/journal/AJB/article-abstract/319903529422

15. Constantiniu S, Romaniuc A, Iancu LS, Filimon R, Tarasi I. Cultural and biochemical character- istics of Acinetobacter spp. Strains isolated from hospital units. J Prevent Med. 2004;12(34):3542.

16. Farahani Kheltabadi R, Moniri R, Shajari G R, Nazem Shirazi M H, Musavi S G A, Ghasemi A et al . Antimicrobial Susceptibility patterns and the distribution of resistance genes among Acinetobacter species isolated from patients in shahid Beheshti hospital, Kashan. Feyz. 2009;12(4) :61-7. http://feyz.kaums.ac.ir/article-1-687-en.html

17. Hujer K, Hulten E, Bajaksouzian S, Adams J, Donskey C, et al. Analysis of antibiotic resistance genes in multidrug-resistant Acinetobacter sp. isolates from military and civilian patients treated at the Walter Reed Army Medical Center. Antimicrob Agents Chemother. 2006;50(12):4114-23. https://doi. org/10.1128/AAC.00778-06 $\quad$ PMID: 17000742 PMCID:PMC1694013

18. Joshi S, Litake G, Ghole V, Niphadkar K. Plasmid-borne extended-spectrum $\beta$-lactamase in a clinical isolate of Acinetobacter baumannii. J Med Microbial. 2003;52(Pt12);11257. https://doi.org/10.1099/0022-1317-52-12-1125 PMID: 14614072

19. Wang S.H, Sheng WH, Chang YY, Wang LH. Healthcare-associated outbreak due to pandrug resistant Acinetobacter baumannii in a surgical intensive care unit. J Hosp Infect. 2003;53(2):97-102. https://doi.org/10.1053/ jhin.2002.1348 PMID: 12586567

20. Michalopoulos A, Falagas ME. Treatment of Acinetobacter infections. Expet Opin Pharmachoter. 2010;11(5):779-88. https://doi.org/10.1517/14656561003596350 PMID: 20210684

21. Karthika RU, Singh SP, Shashikala P, Kanungo R, Jayachandran S, Prashanth K. Correlation between biofilm production and multiple drug resistance in imipenem resistant clinical isolates of Acinetobacter baumannii. Indian J Med Microbiol. 2008;26(4):333-7. https://doi. org/10.4103/0255-0857.43566 PMID: 18974485

22. Rahbar M, Mehrgan H, Aliakbari NH. Prevalence of antibiotic-resistant Acinetobacter baumannii in a 1000-bed tertiary care hospi- 
tal in Tehran, Iran. Indian J Pathol Microbiol. 2010;53(2):290-3. https://doi.org/10.4103/03774929.64333 PMID:20551535

23. Ayan M, Durmaz R, Aktas E, Durmaz B. Bacteriological, clinical and epidemiological characteristics of hospital-acquired Acinetobacter baumannii infection in a teaching hospital. J Hosp Infect. 2003;54(1):39-45. https://doi.org/10.1016/ S0195-6701(03)00076-8 PMID: $\underline{12767845}$

24. Mak K, Kim J, Pham J, Tapsall J, White P. Antibiotic resistance determinants in nosocomial strains of multidrug-resistant Acinetobacter baumannii. J Antimicrob Chemother. 2009;63(1):47-54. https://doi.org/10.1093/jac/ $\underline{\text { dkn454 }}$ PMID: 18988680

25. Snelling AM, Gerner-Smidt P, Hawkey PM, Heritage J, Parnell P, Porter C, Bodenham AR, Inglis $\mathrm{T}$. Validation of use of whole-cell repetitive extragenic palindromic sequence-based PCR (REP-PCR) for typing strains belonging to the Acinetobacter calcoaceticus-Acinetobacter baumannii complex and application of the method to the investigation of a hospital outbreak. J Clin Microbiol. 1996;34(5):1193-202.

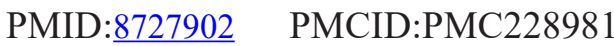

26. Martín-Lozano D, Cisneros JM, Becerril B, Cuberos L, Prados T, Ortíz-Leyba C, Ca-as E, Pachón J. Comparison of a Repetitive Extragenic Palindromic sequence-based PCR method and Clinical and Microbiological methods for determining strain sources in cases of nosocomial Acinetobacter baumannii bacteremia. J Clin Microbiol. 2002;40:4571-5. https://doi.org/10.1128/JCM.40.12.4571-4575.2002 PMID:12454154 PMCID:PMC154637

27. Misbah S, AbuBakar S, Hassan H, Hanifah YA, Yusof MY. Antibiotic susceptibility and REPPCR fingerprints of Acinetobacter spp. isolated from a hospital ten years apart. J Hosp Infect. 2004;58(4):254-61. $\quad$ https://doi.org/10.1016/j. jhin.2004.07.007 PMID:15564001

28. Yan Z, Cao J, Chen R, Wei X, Liu L, Li Xu $\mathrm{X}$. Susceptibility patterns and molecular epidemiology of multidrug-resistant Acinetobacter baumannii strains from three military hospitals in China. Int $\mathrm{J}$ Antimicrob Agents. 2010;35(3):269-73. https://doi.org/10.1016/j.ijantimicag.2009.10.016 PMID:20036519

\section{How to Cite This Article}

kian B, Mirnejad R, Mirkalantari S, Golmohammadi R. Molecular Genotyping of Acinetobacter baumannii Species Isolated from Patients in Tehran, Iran, by Repetitive Element PCR Fingerprinting. Iranian Journal of Pathology, 2018; 13(2): 144-150. 